\title{
MULTI-SIDED PLATFORMS AS NEW ORGANIZATIONAL FORMS
}

\author{
David McIntyre, Providence College \\ dmcinty2@providence.edu \\ Arati Srinivasan, Providence College \\ asriniva@providence.edu \\ Allan Afuah, University of Michigan \\ afuah@umich.edu \\ Annabelle Gawer, University of Surrey \\ a.gawer@surrey.ac.uk \\ Tobias Kretschmer, LMU-Munich \\ t.kretschmer@1mu.de
}

\begin{abstract}
Multi-sided platforms (MSPs) have recently drawn considerable research attention, as the influence of platforms is increasingly relevant across a wide array of industries. However, despite theoretical and empirical advances spanning multiple disciplines, several core questions remain about MSPs. This article offers novel insights around platform business models, platform scale and scope, characteristics of platform "sides", and the role of technology in platform evolution. We hope that these insights provide a useful framework for integrating and advancing various perspectives on the emergence and management of MSPs.
\end{abstract}

The authors would like to acknowledge the guidance of Associate Editor Susanna Khavul and three anonymous reviewers in improving the manuscript. 


\section{INTRODUCTION}

The increasing prevalence of multi-sided platforms (MSPs) has had a significant impact on firm strategy in settings ranging from smartphones to ride-hailing services, as networks of individuals and organizations seek value from compatibility and interaction. In such contexts, platforms often emerge to serve as intermediaries between two or more "sides" which could not easily interact otherwise (Gawer, 2014; Hagiu, 2014; McIntyre \& Srinivasan, 2017; Rochet \& Tirole, 2003; Thomas, Autio \& Gann, 2014, Cusumano, Gawer, and Yoffie, 2019). Understanding the dynamics of platform competition has become a strategic imperative for managers, as many of the world's most lucrative companies are based at least in part on a platform business model. For example, seven out of the ten most valuable companies by market value in 2019 - Apple, Amazon, Alphabet, Microsoft, Facebook, Alibaba and Tencent - operate one or more prominent platforms (Murphy et. al, 2019). In addition, platforms are no longer the exclusive domain of high-technology settings, as their impact can be seen in industries as diverse as food products, credit cards, and textbook publishing. Despite significant advances in this domain of research, numerous challenges and ambiguities about the emergence, persistence, and management of platforms remain.

As the influence of platforms is increasingly apparent across an array of industries, strategic decisions around platform business models, boundaries, ecosystems, and technologies are critical to long-term success. Platform firms operate differently from more traditional firms in that they often need to bring a critical mass of two or more distinct groups of participants together; as such, they require unique strategies that allow them to bring multiple sides on board. While recent research has demonstrated the importance of attracting and leveraging different user groups around the platform (Armstrong, 2006; Gawer, 2014; Hagiu, 2014), many questions 
regarding optimal strategies and structures for platforms remain. How can platform firms create maximum value for their users while at the same time capturing some of that value? Given that platforms often involve broader ecosystems of firms (Adner, 2017; Jacobides, Cennamo \& Gawer, 2018), what are the incentives and outcomes associated with platform firms expanding their scale and scope? How can such firms effectively manage a portfolio of complementors, when such relationships are frequently not bound by formal contracts (e.g., Venkatraman and Lee, 2004; Adner, 2017)? How do platform competitive dynamics change as underlying technologies evolve over time?

To address these issues, this article characterizes multi-sided platforms as a fundamentally novel organizational form, requiring new insights on business models, organizational boundaries, and other unique features of these settings. We briefly highlight three existing perspectives on multi-sided platforms - platform, firm, and ecosystem - summarizing recent advances. We then synthesize and propose to extend extant perspectives on multi-sided platforms, focusing on four key themes which span these streams: MSP business models, scale and scope considerations for platform sponsors, heterogeneity among platform "sides", and the dynamic nature of platform technologies in influencing outcomes in platform-mediated markets.

\section{THREE PERSPECTIVES ON PLATFORMS}

In the modern economy, an increasing number of transactions are organized around multi-sided platforms (MSPs), which facilitate direct interactions among firms and individuals (Gawer, 2014; McIntyre \& Srinivasan, 2017; Rochet \& Tirole, 2003). For example, Airbnb facilitates transactions among providers and seekers of short-term accommodation. In addition, platforms often serve as architectures upon which firms may build related products or services 
(Gawer, 2014), such as the Keurig "K-cup” coffee maker. In some cases, platforms may serve as both intermediary and architecture, such as video game consoles which both facilitate online play among an installed base of users and enable the development of a portfolio of games - or complements - by third-party game developers. The increasing presence of platforms across a variety of industries has sparked a concurrent rise in research around MSP dynamics. These studies have broadly approached such dynamics from three perspectives: the platform, firm, and ecosystem perspectives.

\section{Platform Perspective}

Platform perspectives have focused on the value of a platform to users, with the core premise that network effects have a significant role - i.e., consumers place greater value on a large network of other users of the platform. Underlying this assumption is the notion that platforms are subject to "positive feedback" (Katz \& Shapiro, 1985) and increasing returns to scale (Arthur, 1989) - the larger the platform's installed base of users, the greater the incentives for third parties to introduce more complementary goods and services for the platform, thereby enhancing its value to existing and potential users (Gawer \& Cusumano, 2002; Cusumano, Gawer \& Yoffie, 2019). Building on this work, more recent perspectives have emphasized the role of platforms as intermediaries, as MSPs emerge to mediate transactions among distinct but affiliated user sides (Evans, 2003; Hagiu \& Wright, 2015; Rochet \& Tirole, 2003, 2006), which mutually benefit as each side grows. The presence of indirect network effects - the value that accrues to one side due to the presence of users or complementary goods on another side - has been a cornerstone of research on MSPs (Cusumano and Gawer, 2002; Rochet \& Tirole, 2003; Armstrong, 2006; Cennamo \& Santaló, 2013). As such, one emphasis of the platform perspective has been on explaining the existence of direct and indirect network effects in diverse 
settings, and the subsequent emergence of dominant technological standards (Shapiro, 1999;

Parker \& Van Alstyne, 2005; McIntyre \& Srinivasan, 2017).

\section{Firm Perspective}

Firm-level views of platforms have emphasized the effective growth and management of firm-sponsored MSPs. By "firm" perspective, we are referring specifically to the firm which

owns the focal platform. Research within this realm has coalesced around strategic initiatives related to platform leadership (Gawer and Cusumano, 2002; Gawer and Henderson, 2007) ranging from platform firms' decisions around optimal entry timing (Chintakananda \& McIntyre, 2014) to pricing strategies and platform feature and quality considerations (Claussen, Essling \& Kretschmer, 2015) From the firm perspective, developing and maintaining a large installed base of platform users is thought to represent a critical capability in platform competition. However, recent findings suggest a more nuanced view, illustrating that developing loyalty or strong ties among users (Afuah, 2013; Fuentelsaz, Maicas \& Garrido, 2015) may be more relevant considerations than the total number of users in creating platform value. As platforms evolve, strategic choices around compatibility across generations of technology become more salient, as firms seek to leverage an existing user base across multiple generations of a platform (Kretschmer \& Claussen, 2016), or across multiple platforms simultaneously (Eisenmann, Parker \& Van Alstyne, 2011; Cennamo, Özalp \& Kretschmer, 2018; Özalp, Cennamo \& Gawer, 2018).

\section{Ecosystem Perspective}

The core value created by most MSPs arises from the mediation of interactions among distinct user groups. As such, inter-firm or ecosystem perspectives have attempted to characterize the types of complementarities amongst ecosystem members (Jacobides, Cennamo \& Gawer, 2018) and have increasingly focused on the interactions among the multiple sides of a 
platform - specifically how platform sponsors can attract complementors to the platform (Cennamo \& Santaló, 2013; Kapoor \& Lee, 2013; Rochet \& Tirole, 2003, 2006). Research in this area has emphasized the role of platform owners' decisions - such as the optimal openness of their platforms - in influencing their ability to attract third-party complementors (West, 2003; Parker \& Van Alstyne, 2005; Lee \& Mendelson, 2008; Eisenmann, Parker, \& Van Alstyne, 2011). In addition, studies of strategic interactions with complementors have recently incorporated a more dynamic view of platforms, acknowledging that effective strategies around complements may evolve as platforms mature (Cennamo, 2016). As such, there has been recent interest in understanding how the technological architectures of platforms and governance principles together influence platform evolution (Tiwana, Konsynski, \& Bush, 2010; Gawer, 2014; Anderson, Parker, \& Tan, 2014; Tiwana, 2015; Cennamo, Özalp \& Kretschmer, 2018). While ecosystems are not unique to MSP contexts (Adner, 2017), specific characteristics of different participant sides - complementors and users, for example - are increasingly seen as vital to understanding platform lifecycles (Rietveld \& Eggers, 2017). Recent integration efforts between ecosystem research and inter-organizational networks suggest to bring the ecosystems research focus on modularity and complementarity at the forefront of inter-organizational research while enriching ecosystems scholarship with systematic applications of network analytic tools to map the patterns of component interdependencies (Shipilov and Gawer, 2020).

\section{THE STATE OF PLATFORM RESEARCH}

Recent theoretical and empirical studies have significantly enhanced our understanding of the dynamics of multi-sided platforms. Platform, firm and ecosystem perspectives have moved beyond descriptive scenarios of platform emergence to more nuanced views of the key strategic 
levers by which firms can create and capture value via MSPs. Nonetheless, the increasing prevalence of platforms has highlighted a number of unresolved questions regarding effective strategies and management in these settings. Though the emergence of dominant platforms such as Facebook or Microsoft Windows has been examined from various perspectives, more robust theoretical and empirical evidence about managerial initiatives around platform strategy and structure are largely lacking. In addressing these gaps, four critical themes hold the keys to exploring meaningful research questions around platform value creation and capture. First, optimal business models for emerging and mature platform firms have not been well-established. Second, and similarly, the notion of the platform as a fundamentally new organizational (or meta-organizational) form is compelling (Gawer, 2014), but the implications of this idea for organizational boundaries, governance mechanisms, and platform scope have yet to be fully explored. Third, platform value is often contingent upon the extent to which different "sides" derive value from interaction, yet the specific characteristics of platform sides in driving mutual dependence and value have been largely unaddressed. Fourth and finally, platforms are fundamentally dynamic in nature, yet the majority of extant literature implicitly treats competitive outcomes in the contexts as static (e.g., "winner-take-all" outcomes). How do incentives and strategic considerations around core platform technologies and complementor relationships evolve with platforms?

In the following sections, we explore and propose to extend these four critical themes incorporating elements of platform, firm, and ecosystem perspectives: MSP business models, scale and scope considerations for platform sponsors, heterogeneity among platform sides, and the dynamic role of technology in platform contexts. 


\section{PLATFORM BUSINESS MODELS}

A platform business model is a set of activities for building resources and using them to generate, deliver, and monetize the benefits that users perceive in the platform - that is, the set of activities for creating and capturing value on the platform (Afuah, 2018; Massa, Tucci \& Afuah, 2017, Cusumano, Gawer and Yoffie, 2019). While the mechanisms of platform adoption and diffusion from users' perspective — and value creation from platform owners' perspective — have been widely explored, the factors by which platform owners capture value from their platforms are less clear. That is, relatively little research has examined the conversion of the benefits that users perceive in a platform into profitable revenue streams for the platform owner. Many specific aspects of platform business models, including which side of an MSP pays the owner of a platform, how much the owner is paid and when, the payment methods used, and the cost of the resulting revenue streams, remain ambiguous or dependent upon contextual factors for a given platform (Afuah, 2018). ${ }^{1}$

Value capture in multi-sided platforms is influenced by two rather specific characteristics that platform owners can exploit. First, as described previously, MSPs exhibit network effects because the more users that there are on one side, the more valuable the platform becomes to users on the other side, and vice-versa (Rochet \& Tirole, 2003, 2006). Thus, a platform owner can create value for one side by — for example — expanding the number of users to the other side. Importantly, the platform owner can potentially capture at least some of the value created for one side through payments made by the other sides. Second, in a multi-sided platform, members of one side often interact directly with members of the other side, with the platform owner

\footnotetext{
${ }^{1} \mathrm{~A}$ firm captures value when the revenues that it obtains for the benefits that it offers users exceed the cost of offering the benefits (Lepak, Smith \& Taylor, 2007).
} 
facilitating the direct interaction. Thus, in capturing value, a platform owner can take advantage of these two multi-sided platform characteristics in five areas: the choice of which side to charge, pricing strategy, switching costs, multi-homing costs, and crowdsourcing.

Building on Evans and Gawer (2016), Cusumano, Gawer, and Yoffie (2019) distinguish between two distinct platform business models: "innovation platforms" and "transaction platforms". In innovation platforms, the platform serves as a technological foundation or building block that the platform owner and ecosystem members can share and upon which ecosystem members develop complementary innovations; and the business model of "transaction platforms", where the platform serves as an intermediary for direct exchange or transactions across multiple sides. Both types are subject to network effects. For innovation platforms, at least one side is composed of complementors - that is, developers of complementary innovations.

\section{Which Side to Charge?}

An important part of generating revenues from the benefits that users perceive in a multisided platform is deciding which side to charge and which one to subsidize and when. For example, an advertising revenue model may exploit the network effect property of the platform by subsidizing the more price-elastic side to increase the size of the network, while charging the more price-inelastic side for the right to interact with the other side (Parker \& Van Alstyne, 2005; Rochet \& Tirole, 2006, Hagiu, 2014). Early research about which side to charge focused on strategies to, for example, resolve the chicken-and-egg conundrum early in the life of a platform (e.g., Parker \& Van Alstyne, 2005). An important extension of this work involves the exploration of other specific revenue models for MSPs — such as razor-and-blade, freemium, licensing, etc. - and, importantly, which models are more likely to work early in the life of a platform and which ones in later stages of the life cycle. 


\section{Pricing Strategy}

Perhaps more important than the general monetization strategy is the decision of how much to charge and by how much to subsidize (Afuah, 2018). This is where the platform owner's pricing strategy comes in. Too high a price may drive away users while too low a price-with no strategic motive-leaves money on the table. Abundant research about how much to charge customers in general exists, with actual MSP pricing strategies illustrating many of the dynamics outlined above. Most economic models have focused on demonstrating the efficacy of subsidizing one side of the platform by using deep discounts in order to attract the other side to join (for example, Evans et al., 2006; Parker and Van Alstyne, 2005; Rochet and Tirole, 2003, 2006; Rysman 2009, etc.). For instance, Rochet and Tirole (2003) showed that optimal pricing strategies in platform markets could entail pricing below marginal cost to one side and above marginal cost to the other side. Other studies have relatedly focused on demonstrating diverse settings and industries in which firms serving as platforms set some prices at zero or even below marginal cost (for instance, Evans 2003).

While most of these studies have focused on which side to charge vs. subsidize, additional research is warranted on how platform firms can use dynamic pricing strategies to capture greater value. For example, Uber practices surge pricing in which it charges higher prices for rides during "rush hours" when demand for rides is very high. The idea is to get more drivers out on the roads during rush hour when passengers are also likely to be more willing to pay the higher prices. Clearly, a platform's pricing strategy can be critical to the revenues that it generates and, therefore, to the value that it captures. Thus, future research would benefit from further exploration of not only charging vs. subsidizing different MSP sides, but also when, and how much. Ohashi (2003) shows for example that discounts given by Sony in the early phases 
of the VCR market could have inverted the market outcome and have monopolized the market in Sony’s (Betamax) favor.

\section{Switching Costs}

A platform owner that makes smart choices about which side to charge and which one to subsidize, and by how much, increases its chances of profitability. The problem is that competitors also want to make money, and because a large part of the value of a multi-sided platform is in the number of users, competitors may try to convince users of a focal firm's platform to switch to theirs. Thus, building switching costs - to make it costly for users of a focal platform to switch to another platform — is important to a platform owner's ability to capture value. For example, a platform owner can have members of both sides of a two-sided platform rate each other to signal trustworthiness (Afuah, 2013; Rochet \& Tirole, 2003). If the platform owner prevents users from taking their ratings with them when they switch to other sites, it is building an additional switching cost for the user, since a user that switches has to build a new reputation on a new platform. Importantly, switching costs may increase with the size of a platform's network, since it can be very difficult to take one's learning investments and ties to a totally different network. For example, Microsoft benefited from significant switching costs for users of their Microsoft Office suite due to users' significant investments in learning, and the ubiquity and need for compatibility with the Windows operating system (Kretschmer, 2004).

\section{Multi-homing Costs}

A user is multi-homing when they are concurrently affiliated with more than one platform (Caillaud \& Jullien, 2003; Rochet \& Tirole, 2003). That is, rather than switching completely from one platform to another, a user maintains ongoing relationships with more than 
one platform. Generally, the ability of users to multi-home tends to mitigate opportunities for value capture for platforms. For example, if a seller on eBay multi-homes, eBay loses out on the commission on the items that the seller sells on another auction site. While the ability to multihome would seem to be negatively related to switching costs in many cases, the two terms are often used in conceptual isolation. The specific costs, benefits, and perceived trade-offs to users of the ability to multi-home and/or switch platforms represent a vital next step in this domain (Cennamo, Özalp \& Kretschmer, 2018). Managers would be very interested in when and how one is more likely to give their firms a competitive advantage. Relatedly, multihoming complementors will tend to reduce a platform's scope for competitive differentiation (because competing platforms offer the same, or similar, complements). This may motivate platform owners to "buy exclusivity" from complementors, i.e. to offer especially valuable complementors better conditions or privileged access in return for exclusivity.

\section{Keeping the Costs Low}

The value capture factors that we have explored so far have been largely about revenues, even though value capture is about revenues from benefits minus the costs of generating and monetizing the benefits. The rapid proliferation of new technologies and the concurrent increase in platform business models has reduced the need for platform firms to own and operate their physical infrastructure and assets, thereby allowing them to lower their costs (Parker, Van Alstyne, and Choudary, 2016). Yet, as platform firms strive to facilitate interactions in two-sided markets they face additional costs associated with managing coordination between the two sides, ensuring the quality of complements being offered on the platform and retaining their users when switching costs are low. So the question is: How can platform firms balance the tradeoff between lower infrastructure costs with higher coordination costs? More specifically, are there any 
business models that can be used to keep down the cost of providing benefits for users on multisided platforms? Anecdotal examples suggest that crowdsourcing business models can create value while keeping costs very low. A multi-sided platform owner is crowdsourcing a task when, rather than performing the task by itself or contracting it to a designated contractor, the owner outsources the task such that anyone anywhere can self-select and perform the task with no exante contract (Afuah \& Tucci, 2012). Crowdsourcing drastically reduces the cost of delivering benefits to customers, thereby increasing value capture. However, the specific cost reduction mechanisms of different types of crowdsourcing - from a completely open platform architecture which can be freely enhanced or modified, to more limited arrangements with specific groups of third parties, merit further investigation. Along similar lines, the emergence of online labor markets (OLMs) may lower transaction costs and enable firms to outsource activities previously considered difficult to outsource (Chen and Horton, 2016, Horton and Chilton, 2010)

Anecdotal evidence and the little research that has been conducted about value capture in multi-sided platforms suggests the right choices about who to charge, who to subsidize, pricing strategy, and what switching and multi-homing costs to build can make a significant contribution to the value that a platform owner can capture from its platform. There is still a great deal that future research can tell us about what combinations of these factors are best for which business models, when, how and why.

\section{PLATFORM SCALE AND SCOPE}

The implications of the notion of platforms as a fundamentally new organizational (or meta-organizational) form for platform scale, scope, and boundaries have yet to be fully explored 
(Dushnitsky \& Klueter, 2017). We now outline several strategic perspectives on managing platform scale and scope, and expand on possible extensions of this work.

\section{Demand-Side Economies of Scale}

Network effects between the various "sides" of a platform are seen as so central in economic views of platforms that Rysman (2009: 127) states that "in a technical sense, the literature on two-sided markets could be seen as a subset of the literature on network effects". Network effects are sometimes characterized as demand-side economies of scale (Katz \& Shapiro, 1985: 824; Parker \& Van Alstyne, 2005: 149). While helpful, this characterization makes most sense when all users of a platform are on the same side, as then, more users to a platform beget more users (as in a telephone network, or among Skype users). However, with most multi-sided platforms, network effects occur not exclusively within sides, but across sides, as in when more Uber drivers make Uber a more attractive platform to join for riders, or when more Android developers make Android a more attractive platform to join for app users.

\section{Expanding Platform Scope and Shifting Platform Boundaries}

Given the presence of these network benefits, the question of what causes platform leaders to shift their platform boundaries has recently begun to attract scholarly attention. Why and how should platforms expand their scope? Does the expansion of platforms respond to a logic that is different from traditional firms' expansion? Does it pursue different goals? Does it express itself differently than the expansion of traditional firms? While the earliest models of MSPs considered platforms as fixed, more recent research has started to focus on drivers and consequences of shifts in platform boundaries. Two main themes emerge from this literature: one is concerned with the expansion of the scope of the platform-owning firm, while the other is concerned with the opening up of technological interfaces and rules of access to the platform. 
An important reason why platform owners enter complementary markets can simply be to "get the ball rolling" as, when they launch (whether they launch a new platform, or launch a new version of the platform), they will need complements on one side of the platform to be available in order to attract users on the other side of the platform. A classic example is Nintendo offering the Mario Brothers game at launch, another is Intel offering motherboards that would be compatible with the latest versions of its operating system, or Apple launching the iPad and iPhone with a few bundled applications that it had developed in-house, including a web browser (Safari), Mail, Photos, iTunes, Notes, Contacts, and Calendar (Cusumano, Gawer, and Yoffie, 2019). This is an area where there is not much empirical research yet but a growing interest. For example, Wen and Zhu (2017) find that after Google's entry threat (as proxied by Apple entry, as there had been an observable pattern of Google entering the same app space that Apple had) into various mobile apps, the external app developers reduced innovation and increased prices. But they also find that the app developers' incentives were not completely suppressed and rather that they shifted innovation to unaffected and new apps, which may reduce social inefficiency. A study by Foerderer, Kude, Mithas and Heinzl (2018) on the effect of Google's entry in the market for photography was actually associated with a significant increase of complementary innovation, as measured by other apps' major updates. They explain this phenomenon by a mechanism of increased consumer attention for photography apps.

Yet expansion into adjacent markets can also be driven by several other factors. In their study on platform envelopment, Eisenmann et al. (2011) discuss some of the factors that may drive platform scope's expansion in the context of platform competition. Platform envelopment occurs in the context of competing platforms aiming at overcoming entry barriers. Envelopment entails entry by one platform provider into another's market by bundling its own platform 
functionality with that of the target's, to leverage shared user relationships and common components. It, therefore, affects the scope of the platform, which extends into other markets. Platform envelopment happens for a variety of reasons: "shared user relationships" (which concerns the demand for the platform), but also leveraging "common components" (which concerns the supply of the platform). Eisenmann et al. (2011) show that private economic benefits of platform envelopment are both efficiency-driven as well as power-seeking, by weakening rivals. "Through bundling", Eisenmann et al. (2011, p. 1275) explain, "a market entrant can foreclose a target's access to customers and thereby reduce the target's scale".

Since platform-mediated markets engender economies of scale both through network effects and leveraging fixed costs, they are particularly good candidates for foreclosure attack (Whinston 1990, Carlton and Waldman 2002). Note how in this explanation the efficiencyargument ("economies of scale", "leveraging fixed costs") is advanced together with the (market) power argument ("foreclosure"). To clarify how platform envelopment operates, Eisenmann et al. (2011) make a distinction on whether the "target" market is a complement, a substitute, or unrelated. If the target market is a substitute, "the envelopment is most likely to succeed if the bundling offers significant economies of scope" (in production) (Eisenmann et al. 2011, p. 1281). If the target market is unrelated, the envelopment is most likely to succeed "if user bases overlap significantly and when production economies of scope are high" (Eisenmann et al., 2011, p. 1282). And last, if the target market is a complement, 'due to [modular] product designs that are optimized to reduce functional overlap, attackers who target complements will not normally realize significant [production] economies of scope. Consequently, the envelopment of complements is most likely to succeed with high overlap in platforms user bases' (Eisenmann et al. 2011, p. 1280). Note how the first two platform boundary moves (towards a 
substitute or unrelated target market) respond mainly to production-efficiency logic, whereas the entry into a complementary market follows leveraging overlapping user base and through bundling foreclosing rivals access to the user base, which is not an efficiency argument, but a market power argument.

For monopolistic platform leaders, it is useful to refer to the argument developed by Carlton and Waldman (2002) on the strategic use of "tying" to preserve and create market power in evolving industries. Tying consists in refusing to sell product A to a consumer unless the consumer also purchases product B. Carlton and Waldman (2002), building on Whinston (1990), have shown that a monopolist, by tying a primary good in its initial market to a complementary good subject to network effects in a newly emerging complementary market, can sustain its market power in its initial market and that it can also "swing" or transfer its initial monopoly to the newly emergent complementary market. Carlton and Waldman (2002) explain that some ties can be achieved not only through contracts and pricing but also, as in the case of IBM in the 1970s, through product design ${ }^{2}$. Expanding the scope of a platform (including functionality B to a platform A) is a product design decision that can, therefore, be seen as an economic equivalent to tying. Expanding platform scope can, therefore, be used strategically to win non-efficiencyrelated gains by either foreclosing rivals or deterring entry by complementors which may turn into rivals.

Returning to the question of gaining market power over rivals in the context of competitive rivalry, another means to achieve this without resorting to scope expansion can be observed when platform leaders unilaterally change the degree of openness of their platforms to

\footnotetext{
2 In the 1970s, there was an allegation against IBM that IBM's new central processing unit was interface incompatible with the plug-in components of rivals - a tie achieved through product design (Carlton and Waldman 2002, p. 197).
} 
external-facing technical interfaces. In particular, selectively closing platform boundaries is sometimes used as either a pre-emptive or retaliatory tactic against a former complementorturning-into-rival. A well-known example concerns Apple's decision to selectively close its interface to Adobe's Flash player in 2010. At the time, Apple CEO Steve Jobs explained in a famous published letter, that one of the main reasons why Apple would selectively close its iPhone, iPad and iPod interfaces to Adobe's video player Flash was a refusal to become dependent (Jobs used the wording "at the mercy", a power-laden concept) upon a third-party "deciding if and when they will make our enhancements available to our developers", as it would "hinder the development and progress of the platform". ${ }^{3}$ Another case in point is when Twitter changed its API in 2012, preventing users' Tweets from appearing on the rival social networking platform LinkedIn (previously perceived as a complementor), as an attempt to cease adding value to LinkedIn and therefore stop fueling the growth of LinkedIn with Twitter content. ${ }^{4}$ Closing the platform interface can therefore be used to weaken rivals in the context of growing competition from complementors.

Competitive interaction is not the only driver of platform boundary shifts. Such shifts are also associated with platform owners aiming to tap into external sources of innovation. For example, Boudreau $(2010,2012)$ shows in his studies on how “opening up" a platform's interfaces stimulates the generation of innovation by external complementors. Boudreau (2010) examines over 14 years the evolution of complementary innovation associated with mobile handheld platforms. He finds that granting greater levels of access to platform complementors (in this case independent hardware developer firms) resulted in up to a five-fold acceleration in the

\footnotetext{
3 Source: Steve Jobs, "Thoughts on Flash", 29 April 2010. http://www.apple.com/hotnews/thoughts-on-flash/

${ }^{4}$ Source: http://linkedinprofileservice.co/linkedin-profile/linkedin-profiles/twitter-stops-no-longer-displays-tweets-on-linkedinprofiles/.
} 
rate of new handheld device development. Over time, he finds an inverted U-shape relationship between innovation and opening platform access, which is consistent with a hypothesis of "crowding out" of innovation incentives when competition among complementors increases beyond a certain level) $)^{5}$. Boudreau (2012) confirms that the "crowding out" of innovation incentives happens due to the high degree of competition between complementors themselves.

More recently, Boudreau (2017) finds that platform technology boundaries and platformowner boundaries vary independently, and therefore that these two variables should not be conflated. In examining the extent to which narrowing or widening of platform technology boundaries affects (1) investment incentives; (2) internalizing coordination problems; and (3) consolidating control over critical assets, he finds significant cross-sectional variation and changes over time in platform-owner boundary choices, suggesting therefore that these are neither given nor pre-determined by industry conditions. He finds that rather than an unavoidable trade-off of "openness-versus-control," most successful platform owners create boundaries that balance openness to outside developers with maintaining coordination across the entire system.

We can see that decisions to open or close the platform technological interface can interact with decisions to expand the scope of the platform firm. We also note that while technology choices on platform design and interfaces have an influence on complementors' incentives to innovate, and can affect to some extent complementors' capability, they constitute only one of the levers of action that platform owners can manipulate. The scope of the platform is another lever of action. But more generally, the issues of drivers of investment incentives and control of critical assets across the ecosystem are dynamic issues that require more research on

${ }^{5}$ This relationship is well-known in the innovation literature (Aghion, Bloom, Blundell, Griffith and Howitt, 2005). 
the identification of the multiple ways in which platform owners govern their ecosystem and specifically how they manage the various platform sides. The next section examines these issues.

Several questions on platforms scope deserve further attention. For example, while platforms such as Facebook, Google, or Amazon have expanded the scope of their platform regularly over time, either organically or through acquisition, not all platforms follow an expansionary trajectory. For example, knowledge marketplaces who match entrepreneurs or inventors, and investors or licensees tend to remain narrowly focused in scope (Dushnitzky \& Klueter, 2017). Empirical research on a variety of industries is needed to gain a better understanding of the influence of the industry and the main activity performed by the platform on the scope decision. Such research is important as we risk otherwise to develop theory on a small subset of the platform phenomenon and derive conclusions that would be driven by industry effects.

We also need more research that examines the effect of specific acquisitions by platforms and analysis of the post-acquisition integration. The extant research examines and proposes mechanisms for why these acquisitions take place. But despite the widely discussed in the business press acquisitions of DoubleClick by Google, WhatsApp by Facebook, Shazam by Apple, and of LinkedIn by Microsoft, there is still little empirical research in this area, with Li and Agarwal (2016) study of Facebook's integration of Instagram an exception. The rationale of efficiency is usually advanced by the acquirer when proposing the acquisition, but in the context of concentration of market power, and a global trend toward increased regulatory scrutiny over digital platforms acquisitions, there have been calls to assess whether the current regulations with regards to acquisitions should be strengthened, with recent hearings in October 2018 at the U.S. Federal Trade Commission on competition and consumer protection and multi-sided platforms, 
expert panels advising the European Commission, and reports from experts to the UK government (Furman, Coyle, Fletcher, McAuley, \& Marsden, 2019). The regulators' concern is whether the systematic acquisition by platforms of nascent competitors is used to maintain market power (what Cunningham, Edener and Ma (2018) call "Killer Acquisitions” acquisitions with the sole intent of taking the target out of business), and the role of data acquisition to raise barriers to entry. Empirical research in this area would therefore provide useful elements to regulatory development.

\section{HETEROGENEITY AMONG PLATFORM SIDES}

One of the most prominent features of many platforms is the fragmented nature of sides mediated by the platform. That is, while it is not uncommon that consumers tend to be highly fragmented and heterogeneous in their preferences, many platforms, most notably "sharing" platforms, will have entrepreneurial providers or even individuals contributing complements to the platform. This fragmentation tends to change the supply dynamics, as contracts with bilateral bargaining between strong partners are less likely to dominate. Rather, incentives and nudges to attract the "right" kind of complementors and an attractive "mix" of them to the platform form part of the toolbox of platform owners. Research on these instruments and their effectiveness is currently still lacking. What are the kinds of complementors that platform owners want to attract to their platforms? How can platform firms strategically attract the right kinds of complementors? How can platform firms successfully leverage the right mix or balance of complementor heterogeneity to drive success?

\section{Drivers of Complementor Heterogeneity}


Increasingly, companies such as Microsoft, Uber, Netflix, GE and others recognize the importance of platforms and are positioning themselves in complex, dynamic ecosystems involving partners who are central to their platform strategies (Srinivasan \& Venkatraman, 2018). In such settings, the complementor side of the MSP is gaining prominence due to its growing importance in driving platform success. Third-party software developers have had a significant impact on the emergence and persistence of Microsoft's Windows operating system (Bresnahan \& Greenstein, 1999) in the personal computer market during the 1990s, and more recently on Apple's and Google's success with iPhone and Android.

When these new MSPs emerge or existing platforms evolve, they require the coordination of complementor product launches for success (Shapiro \& Varian, 1998). A complementor tightly coupled to a platform commits significant resources to align their knowledge and routines around a given platform's architecture. In doing so, they are closely aligning their performance outcomes to that of the platform. This commitment to a single platform may render them unable to adapt to changing platform dynamics and thus make them less likely to migrate to newer competing platforms - in essence, increasing their own multihoming costs. For instance, Zynga's tight coupling to the Facebook platform meant that its games didn't diffuse as quickly, and its success was largely tied to the fortunes of Facebook. This proved beneficial for Facebook, as Zynga's games were exclusively available only on the Facebook platform and accounted for about 15\% of Facebook's revenues.

Relatedly, the prior experience of complementors impacts the variety, quality and exclusivity of their complements for a platform. Often, new app development firms are started by teams with previous experience in development. For example, a significant number of video game development firms - such as Radical Entertainment and Valve Software - were started by 
former employees of established incumbents such as Electronic Arts, Microsoft and IBM. This breadth of experience implies that these new complementors might be better able to apply their existing capabilities and knowledge to simultaneously support multiple platforms. For instance, a large part of Rovio's success can be tied to its ability to rapidly launch games across multiple platforms after its success with the iPhone operating system.

In industries that are crowded with multiple competing MSPs, signaling the superiority of a platform is critical to gain end users (Dube, Hitsch \& Chintagunta, 2010). Rochet \& Tirole (2003) introduce the notion of "marquee buyers" who make the platform more attractive to sellers. For MSPs, the ability of the platform to garner support from "marquee" complementors can serve as a signal for the overall popularity of the platform. For instance, in the video game industry, the presence of high quality "superstar" software game titles has been associated with higher video game console sales (Binken \& Stremersch, 2009). While support from wellestablished and high-status complementors can signal status and legitimacy, connections with dominant complementors can also provide access to superior resources (Ahuja, 2000). For example, for video game console manufacturers, developing relationships with dominant game publishers - who have the most resources to invest in the advertising and promotion of their games - could translate into greater visibility and popularity of the video game console itself. Yet, despite the advantages for support from high-status complementors, such "star" complementors are unlikely to be tightly coupled to single platforms and instead increase the availability of their complements across multiple platforms simultaneously. The support of complements for platforms can be threatened by intergenerational platform-technology transitions: even when platform owners have garnered the support of complementors during one technology generation, disruptive innovation in the platform technology introduces challenges 
for ecosystem developers. For example, in a study of 12 videogame platform technology transitions, Özalp, Cennamo, and Gawer (2018) find that as platforms incorporate increased capabilities that make their platform technology more powerful, they also end up increasing the complexity of the development work for their complementors who show - for highly complex, advanced platforms - a pattern of complementors' defection toward rival, less challenging platforms.

In summary, while a key driver of platform success is the number of complementary goods available, over time, the mere number of available complements may not necessarily lead to sustained platform success (McIntyre \& Srinivasan, 2017). Instead, the overcrowding of platforms with complements can lead to the availability of many poor-quality complements, which in turn can negatively affect the user experience and subsequently the dominant position of the platform (Boudreau, 2011). Quality considerations of complements are important across a wide array of platform settings, such as the quality of games available on video game platforms, the quality of products offered by third-party sellers on e-commerce platforms such as Alibaba, and the quality of drivers for Uber. Additional research is thus warranted on the types of governance mechanisms platform firms can employ to manage the tradeoff between the quality and the availability of a large number and variety of complements, and how platform firms can leverage heterogeneity in user preferences to create a differentiation advantage.

The quality of relationships that platform firms establish with complementors can, in part, determine the extent to which a platform continues to thrive (Yoffie \& Kwak, 2006). Such relationships are likely to be a function of complementor age, size, prior experience and ability to adapt to innovations. Next, we discuss how platform firms can effectively navigate these differences in complementors to achieve sustained success. 


\section{Strategies for Optimal Management of Complementor Heterogeneity}

Heterogeneity in complementor attributes and the type of support they provide plays a critical role in driving the competitive outcomes for platform firms. As such, the strategic management of their ecosystem of complementors is crucial to the long-term viability of platform firms. For instance, theoretical logic specifies that the differentiation advantage of platforms is diminished when the same set of complements is available across competing platforms (Landsman \& Stremersch, 2011; Cennamo \& Santaló, 2013; Cennamo, Özalp \& Kretschmer, 2018). Yet, complementors - especially, large, well-known complementors - are likely to seek economies of scope by spreading their set of complements across multiple platforms (Srinivasan \& Venkatraman, 2018). How, then, do platform firms balance the tradeoff between support from large and resource-rich complementors and the availability of exclusive complements to enhance the platform's differentiation advantage? Additional research is needed to understand the optimal mix of number and variety of complements, presence of "superstar" complements and availability of exclusive complements to maximize the benefits of indirect network effects.

Specifically, the influence of network effects can be augmented by resource commitments from both platform providers and independent complementors. Platform firms make investments in generating an ecosystem of complementors, who in turn devote resources to support one or more core platforms (Venkatraman \& Lee, 2004). Since indirect network effects arise when third parties consciously align their products with the platform's architecture, a critical driver of complementor support is the underlying architecture of the platform (McIntyre \& Subramaniam, 2009, Cennamo, Özalp \& Kretschmer, 2018). Thus, platform firms need to 
carefully plan the design of their architectures to augment their set of complements to achieve competitive advantage.

In digital platform settings, complementors may require access to specific technological resources to be able to successfully launch complementary products and cope with the complexity of these settings. For digital MSPs, these resources are often in the form of toolkits that provide training, interface guidelines, and libraries of common modules that new ventures can use in their applications (Von Hippel \& Katz, 2002; Evans, Hagiu \& Schmalensee, 2006). As such, the stronger the relationships that platforms can establish with complementors through the provision of these resources, the higher the likelihood of receiving preferential advantages from complementors in the form of superior or exclusive complements.

Finally, platform firms make deliberate choices around their complementor network to maximize the value to the "other side". While in most situations, the sheer size of multiple participant networks represents a strong indicator of mutual value, in certain contexts, having a large participant network on one side may be a hindrance as it increases the search cost for users on the other side. In these settings, the presence of key users might be more valuable than network size alone. For instance, in the online dating market, eHarmony deliberately limited membership by screening out casual participants to provide a better experience to its core user base and provide a unique advantage over competitors such as Match.com (Halaburda \& Oberholzer-Gee, 2014). Developing relationships with complementors to foster strong mutual dependence across both sides of the platform is, thus, crucial to long term success. Additional studies on how and when size, exclusivity or the presence of "marquee" users (Rochet \& Tirole, 2003) creates more value are needed to better understand the dynamics of platform competition. 
To summarize, future research on heterogeneity among MSP sides would benefit from more robust theorizing and examination of platform-complementor interactions, such as the impact of exclusive complements (Corts \& Lederman, 2009; Srinivasan and Venkatraman, 2010; Cennamo \& Santaló, 2013), variety in available complements, and the ability of platform sponsors to create an effective mix or portfolio of complements.

\section{THE DYNAMIC ROLE OF PLATFORM TECHNOLOGY}

Existing MSP research typically considers one generation of a platform technology. In formal models, this is for analytical convenience; in empirical studies, the rationale is partly related to data availability, partly to keep the technological parameters comparable in a ceteris paribus analysis. While these are valid reasons to focus on single generations, it also means missing out on some important aspects of platform dynamics and competition. Some of these aspects relate to the previous sections, as technological parameters are (at least to some extent) a choice variable that will affect incentives for complementors to join and invest into a particular platform. However, others are inherent to the dynamic nature of many platforms and the fact that platform competition is "reset" to some extent every time technologies progress and open up new possibilities for complementors and consumers to engage with the platform (Kretschmer \& Claussen, 2016). Hence, some important questions platform research can and should ask are: What are the key technological parameters that determine the success of a platform? What is the optimal rate of technological progress of platforms in a dynamic environment? What role do the investment incentives of complementors and the cost of joining a platform (especially for consumers) play? Finally, how can a platform sponsor utilize this knowledge to position themselves favorably in a multistage competition with other platform sponsors? 


\section{Technological Parameters for Platform Success}

The standard assumption of most studies of platforms is that the baseline technology of the platform is a given, or exogenous parameter (e.g. Rochet \& Tirole 2003, Hagiu 2005). For the study of, say, optimal pricing or optimal variety on a given platform, this is appropriate. However, technological quality is often a choice variable for platforms, e.g. in the choice of processor for a video game console. What, then, is the role of innovation or technological quality in the success of a platform? Prima facie, the connection would seem trivial: the better the baseline technology, the more successful the platform, especially if the platform is in competition with others of similar or lower quality (Tellis, Yin \& Niraj, 2009; McIntyre 2011; Zhu \& Iansiti, 2012). This suggests that platform firms have strong incentives to innovate even in the absence of strong competition. However, Claussen, Essling \& Kretschmer (2015) show that the connection is more intricate in a setting in which the overall desirability of the platform is driven by the platform itself and the complements available for it. In the market for PC games, they find that while higher quality baseline technology will attract better complements on average, it also imposes a higher cost of investment on complementors, creating entry barriers for them. Moreover, consumers may not have access to the latest baseline technology, which then implies that not all complements are available to all consumers, reducing the market size for some complements.

Related to the baseline technology's quality is its technological complexity (Cennamo, Özalp \& Kretschmer, 2018). While the two seem closely connected, they have different consequences. Specifically, a complex platform architecture will not likely be felt or registered by end-users other than through the platform's quality. However, a complex architecture affects complementary good producers more intricately (Özalp, Cennamo \& Gawer, 2018). First, it is 
more costly to produce a complement for a complex platform, which will likely change the structure of complements to contain fewer, but higher-quality complements as the higher costs have to be justified by higher revenues. Second, however, these investments are more specific as they have to be tailored to an idiosyncratic platform architecture rather than a generic, simple one. This has important implications for the distribution between single- and multihoming complements. Multihoming complements will face significant costs of porting the complement from a complex platform to a less complex one (Cennamo et al., 2018) as the investments are more specific.

Finally, the decision to make a platform technically compatible (or not) with substitute products is an important parameter in the evolution of a platform. Compatibility lowers switching costs, which may benefit smaller platforms especially, but it also limits the degrees of technological freedom that platforms have for incorporating improvements. There are two aspects of compatibility particularly salient for platform products. First, technological dynamism implies that backward compatibility is an important strategic consideration (Kretschmer \& Claussen 2016, Shapiro \& Varian 1999). Here, ensuring backward compatibility limits technological progress, while it helps overcome the "chicken-and-egg" problem of new platform generations. Second, complements can often be produced (e.g. video games) for multiple platforms - i.e., multihomed. In such cases, platforms may be technologically different (and incompatible as such), but complementors may be able to develop the outwardly same complement for different platforms, thus making the look-and-feel of the platforms more similar.

\section{Strategies for Firms}

Platform owners can try to maintain their market position over time through several strategies. While these are not mutually exclusive, we separate them simply to illustrate their 
focal point of intervention. First, the platform itself can change over time. Second, the interaction between platform and complements can be actively managed by the platform owner, and finally, the market for complements itself can be affected by the platform owner.

Platform Improvements. Platforms, especially technology-based ones, face increasing possibilities for improved functionality, better baseline technology and more sophisticated complementary goods. Still, even if technological improvements and opportunities were continuous, platforms cannot be upgraded constantly. Consumers may resent constant updates with fixes, new functionalities etc., so that platform improvements are often introduced in batches and at discrete time intervals. Why do platform owners not take advantage of the continuous availability of opportunities for improving platform performance? First, product introductions come with launch costs, so the expected benefits from launching a better technology must be weighed up against the (fixed) costs of launching it (Shy, 1996). If the technological improvement is not sufficiently high, introducing a new generation is not profitable. This tradeoff will be especially salient for technology-intensive platforms such as video game consoles or computer operating systems. Second, consumers and complementors desire compatibility with their existing platform generation. Therefore, continuous upgrading of the platform itself may reduce compatibility across complements and users who joined the platform at different times. Indeed, every new platform introduction risks a splintering of network effects across generations (Kretschmer, 2008; Simcoe and Watson, 2018). Platform owners are therefore likely to introduce new platform generations in spaced intervals, which creates a different dynamic among competitors (Chintakanda \& McIntyre, 2014). Competitors will jockey for a leading (early-mover) position for a new generation rather than simply 
introducing their new platform whenever it is ready. Future research could therefore look at the dynamics of the introduction of new generations in markets with competing platforms.

Platform-Complement Interactions. Platforms work because the complements available for a particular platform confer network externalities on the platform itself and thus increase the attractiveness for users. However, the strength of network effects is typically taken as given or estimated across all complements. Yet the extent to which a complement strengthens the platform itself can be a choice by the platform owner, at least to some extent. For example, earlier platforms like Windows actively tried to limit the information they gave to third-party software developers. While this may have strengthened the market position of, say, the Microsoft Office Package, it may have come at the cost of lower variety and complementarity of third-party software with the platform product itself. As many platforms now have come to rely on a healthy ecosystem of first- and third-party complements, reducing complementarities between third-party complements and platform seems a less promising strategy these days. Indeed, platforms may even choose to make complements from previous generations compatible with the current platform generation. This is an important strategic consideration by platform owners. Kretschmer and Claussen (2016) find that while making a new generation (of video game consoles) backward compatible with the old one from the same manufacturer increases end-user demand for the platform itself, it also reduces the incentives of complementors to develop complements for the new generation because there are close substitutes available. In the context of video game consoles, the demand-enhancing effect dominates the supply-reducing effect, but in settings in which the incentives of complementors react strongly to changes in the market structure for complements, the negative effect of backward compatibility may end up affecting the overall success of the platform negatively. 
Complementor Market. Finally, platform owners can also influence the market for complements directly or indirectly. This is one of the core differences between platform markets and market with indirect network effects: The complementary goods market for platforms is typically served by a mixture of first- and third-party complements. As discussed before, a key consideration is the policy regarding exclusivity of complements. While multihoming strategies have become more common in recent years, exclusivity allows platform owners to differentiate themselves from their rivals (Cennamo, Özalp \& Kretschmer, 2018). If exclusivity with thirdparty suppliers is difficult to negotiate, perhaps due to the increasing market power of complementors or a weak competitive position of a particular platform vis-à-vis its rivals, platform owners can achieve a mix of multihoming complements (to establish a critical mass of games and sufficient variety) and exclusive complements (to achieve competitive differentiation from its rivals) by producing some complements itself. Nintendo, for example, has traditionally had a history of providing a high share of first-party exclusive games, especially in the early stages of a console generation. Related to this is the arrangement of contracts with third-party suppliers of platform complements. Offering subsidies, either through development kits that lower the cost of developing (digital) complements or through offering favorable licensing terms, will enable the firm to influence the complementor ecosystem in its favor. Here, complementors have to be rewarded for offering exclusivity (and thus forgoing potential revenues on multiple platforms) through more favorable contract terms. Clearly, more research on the contractual arrangement and the choices of when exclusivity is likely to be preferable both to platform owner and complementor is needed. 
Insert Table 1 about here

\section{CONCLUSION}

With the emergence of multi-sided platforms across a diverse array of settings such as video game consoles, ride-hailing services, and single-serving coffee-makers, an increasing number of theoretical and empirical studies have explored the dynamics of platform emergence and optimal strategies in platform-mediated markets (e.g., Afuah, 2013; Boudreau \& Jeppesen, 2015; Gawer, 2014; Hagiu \& Wright, 2015; Koski \& Kretschmer, 2005; Thomas, Autio \& Gann, 2014; Cusumano, Gawer \& Yoffie, 2019). However, many of these studies explore specific aspects of platforms, such as network or architectural characteristics, without accounting for the broader interplay of firm, platform, and ecosystem dynamics. In addressing this limitation, we have offered four critical themes which span these perspectives for advancing our understanding of multi-sided platforms: MSP business models, scale and scope considerations, heterogeneity among platform sides, and the dynamic nature of platform technologies. Table 1 summarizes the key issues addressed in each of themes, as well as critical next steps in exploring platform dynamics.

While each of these themes has the potential to advance our understanding of platforms, there are also questions at the intersection of multiple themes. For instance, as platforms expand in scale and scope, how might their pricing strategies evolve? Similarly, while creating switching costs for users is an important element of platform business models, an understanding of the 
underlying platform technology and its specific features is required to effectively leverage these costs. Another important issue at the nexus of platform technology and complementor relationships is how platform firms make technological choices - such as the extent of platform openness - to enhance both the availability and quality of complements. As platform boundaries expand and platform firms enter into complementor markets, what are the consequences for their relationships with existing complementors? In turn, what impact might the interplay of these actions have for the long-term durability (or exit) of platforms, phenomena which remain largely unexplored in this literature (e.g., Josefy et. al, 2017)?

We hope that this work will have significant implications for future research and practice in this domain. While the emergence of multi-sided platforms has been studied extensively, such studies are often industry-specific, emphasizing seemingly idiosyncratic industry-level factors influencing platform growth. We hope that this work continues the nascent shift in focus toward platforms as both planned organizational forms and strategic levers by which managers can proactively create and capture value. 


\section{REFERENCES}

Adner, R. 2017. Ecosystem as structure: An actionable construct for strategy. Journal of Management 43(1): 39-58.

Afuah, A. 2013. Are network effects really about size? The role of structure and conduct. Strategic Management Journal 34(3): 257-273.

Afuah, A.N. 2018. Business Model Innovation: Concepts, Analysis and Cases. Second Edition. New York: Routledge.

Afuah, A., Tucci, C. 2012. Crowdsourcing as a solution to distant search. Academy of Management Review 37(3): 355-375.

Ahuja, G. 2000. The duality of collaboration: Inducements and opportunities in the formation of interfirm linkages. Strategic Management Journal, 21(3, Special Issue: Strategic Networks): 317-34

Anderson Jr., E. G., Parker, G. G., Tan, B. 2014. Platform performance investment in the presence of network externalities, Information Systems Research (25):1: 152-172.

Aghion, P., Bloom, N., Blundell, R., Griffith, R., Howitt, P. 2005. Competition and innovation: An inverted-U relationship. Quarterly Journal of Economics, 120(2): 701-728

Armstrong, M., 2006. Competition in two-sided markets. RAND Journal of Economics 37: 668-691.

Arthur, W.B. 1989. Competing technologies, increasing returns, and lock-in by historical small events. Economic Journal 99: 116-131.

Binken, J.L., Stremersch, S. 2009. The effect of superstar software on hardware sales in system markets. Journal of Marketing 73(2): 88-104.

Boudreau, K.J., 2010. Open platform strategies and innovation: granting access vs. devolving control. Management Science 56 (10): 1849-1872.

Boudreau, K.J., 2012. Let a thousand flowers bloom? An early look at large numbers of software app developers and patterns of innovation. Organization Science, 23(5), pp.1409-1427.

Boudreau, K., Jeppesen, L. 2015. Unpaid crowd complementors: The platform network effect mirage. Strategic Management Journal 36(12): 1761-77

Boudreau, K., 2017. Platform boundary choices and governance: Opening-up while still coordinating and orchestrating. In Furman, J., Gawer, A., Stern, S, \& Stern, S (Eds.) Entrepreneurship, Innovation and Platforms. Advances in Strategic Management, Vol. 37, 227-297. Emerald.

Bresnahan, T.F., Greenstein, S. 1999. Technological competition and the structure of the computer industry. Journal of Industrial Economics 47(1): 1-40.

Caillaud, B., Jullien, B. 2003. Chicken-and-egg: competition among intermediation service providers. RAND Journal of Economics 34: 309 - 328.

Carlton, D.W., Waldman, M. 2002. The strategic use of tying to preserve and create market power in evolving industries. RAND Journal of Economics 33(2): 194-220.

Cennamo, C. 2016. Building the value of next-generation platforms: The paradox of diminishing returns. J. Manag. ePub ahead of print July 15, 2016, doi: 10.1177/0149206316658350.

Cennamo, C., Santaló, S. 2013. Platform competition: Strategic trade-offs in platform markets. Strategic Management Journal 34(11): 1331-1350. 
Cennamo C., Özalp, H., Kretschmer, T. 2018. Platform architecture and quality trade-offs of multihoming complements. Information Systems Research29(2): 461-478..

Chen, D.L., Horton, J. J. 2016. Are Online Labor Markets Spot Markets for Tasks? A Field Experiment on the Behavioral Response to Wage Cuts. Information Systems Research 27: 403-423.

Chintakananda, A., McIntyre, D. 2014. Market entry in the presence of network effects: A real options perspective. Journal of Management 40: 1535-1552.

Claussen, J., Essling, C., Kretschmer, T. 2015. When less can be more - setting technology levels in complementary goods markets. Research Policy 44(2): 328-339.

Corts, K.S., Lederman, M. 2009. Software exclusivity and the scope of indirect network effects in the U.S. home video game market. International Journal of Industrial Organization 27: 121-136.

Cusumano, M.A., Gawer, A. 2002. The elements of platform leadership. MIT Sloan Management Review. 43 (3): $51-58$

Cusumano, M.A., Gawer, A., Yoffie, D.B. 2019. The Business of Platforms: Strategy in the Age of Digital Competition, Innovation, and Power. New York: HarperBusiness.

Cunningham, C., Ederer, F., Ma, S. 2018. Killer Acquisitions, Working Paper. London Business School.

Dubé, J. P. H., Hitsch, G. J., Chintagunta, P. K. 2010. Tipping and concentration in markets with indirect network effects. Marketing Science 29(2), 216-249.

Dushnitsky, G., Klueter, T. 2017. Which industries are served by online marketplaces for technology? Research Policy 46 (2): 651-666.

Eisenmann, T., Parker, G., Van Alstyne, M., 2011. Platform envelopment. Strategic Management Journal $32(12), 1270-1285$.

Evans, D.S. 2003. Some empirical aspects of multi-sided platform industries. Review of Network Economics 2: 191-209.

Evans, D., Hagiu A., Schmalensee, R. 2006. Invisible Engines: How Software Platforms Drive Innovation and Transform Industries. MIT Press: Cambridge, MA.

Evans, D.S., Schmalensee, R. 2015. The antitrust analysis of multi-sided platform businesses. In Oxford Handbook of International Antitrust Economics (R.D. Blair and D.D. Sokol, eds.), Oxford: Oxford University Press, 404-447.

Evans, P.C, Gawer, A. 2016. The rise of the platform enterprise: A global survey. The Centre for Global Enterprise. The Emerging Platform Economy Series No.1.

Foss, N.J., Saebi, T. 2017. Fifteen years of research on business model innovation: how far have we come, and where should we go? Journal of Management 43(1):200-227.

Foerderer, J., Kude, T., Mithas, S., Heinzl, A. 2018. Does platform owner's entry crowd out innovation? Evidence from Google photos. Information Systems Research 29(2): 444-460.

Fuentelsaz, L., Garrido, E., Maicas, J.P. 2015. A strategic approach to network value in network industries, Journal of Management 41(3): 864-892.

Furman, J., Coyle, D., Fletcher, A., McAuley, D., Marsden, P.: Unlocking digital competition. Report of the Digital Competition Expert Panel, London 2019, U.K. Government.

Gawer, A., 2009. (Ed.). Platforms, Markets and Innovation. Edward Elgar, Cheltenham, UK and Northampton, Mass.

Gawer, A., 2014. Bridging differing perspectives on technological platforms: Toward an integrative 
framework. Research Policy, 43(7), 1239-1249.

Gawer, A., Cusumano, M.A., 2002. Platform Leadership: How Intel, Microsoft, and Cisco Drive Industry Innovation. Harvard Business School Press, Boston, Mass.

Gawer A., Henderson R. 2007. Platform owner entry and innovation in complementary markets: Evidence from Intel. Journal of Economics and Management Strategy 16(1): 1-34.

Hagiu, A. 2005. Pricing and commitment by two-sided platforms. The Rand Journal of Economics 37: $720-737$.

Hagiu, 2014. Strategic decisions for multi-sided platforms. Sloan Management Review, 55(2).

Hagiu, A., Wright, J. 2015. Multi-sided platforms. International Journal of Industrial Organization. 43: 162-174.

Halaburda, H., Oberholzer-Gee, F. The limits of scale. Harvard Business Review, 92(4): 94-9, 134.

Horton, J. J., Chilton, L. B. 2010. The labor economics of paid crowdsourcing. Proceedings of the 11th ACM conference on Electronic commerce, ACM, 209-218.

Jacobides, M.G., Cennamo, C., Gawer, A. 2018. Towards a theory of ecosystems. Strategic Management Journal 39(8): 2255-2276.

Josefy, M.A., Harrison, J.S., Sirmon, D. G., Carnes, C.. 2017. Living and dying: Synthesizing the literature on firm survival and failure across stages of development. Academy of Management Annals 11 (2): 770-799.

Katz, M.L., Shapiro, C. 1985. Network externalities, competition, and compatibility. American Economic Review, 75(3), 424-440.

Kapoor, R., Lee, J. M. 2013. Coordinating and competing in ecosystems: How organizational forms shape new technology investments. Strategic Management Journal 34(3): 274-296.

Koski, H., Kretschmer, T. 2005. Entry, standards, and competition: Firm strategies and the diffusion of mobile telephony. Review of Industrial Organization 26(1): 89-113.

Kretschmer, T. 2004. Upgrading and Niche Usage of PC Operating Systems. International Journal of Industrial Organization 8-9(22): 1155-1182.

Kretschmer, T. 2008. Splintering and inertia in network industries. The Journal of Industrial Economics 56 (4): 685-706

Kretschmer, T.,Claussen, J. 2016. Generational transitions in platform markets - the role of backward compatibility Strategy Science 1(2):90-104

Landsman, V.,Stremersch, D. 2011. Multihoming in two-sided markets: A empirical inquiry in the video game console industry. Journal of Marketing 75(6): 39-54.

Lepak, D.P., Smith, K.G. Taylor, M.S., 2007. Value creation and value capture: A multilevel perspective. Academy of Management Review 32(1): 180-194.

Lee D., Mendelson, H. 2008. Divide and conquer: Competing with free technology under network effects. Production \& Operations Management 17(1): 12-28.

Li, Z.,Agarwal, A. 2017. Platform Integration and Demand Spillovers in Complementary Markets: Evidence from Facebook's Integration of Instagram. Management Science, 63 (10): 3438-3458.

Massa, L., Tucci, C.L., Afuah, A. 2017. A critical assessment of business model research. Academy of Management Annals, 11(1): 73-104. 
McIntyre, D. 2011. In a network industry, does product quality matter? Journal of Product Innovation Management, 28 (1): 99-108.

McIntyre, D., Srinivasan, A. 2017. Networks, platforms, and strategy: Emerging views and next steps. Strategic Management Journal 38 (1): 141-160.

McIntyre D., Subramaniam M. 2009. Strategy in network industries: A review and research agenda. Journal of Management 35: 1494-1517

Murphy, A., Ponciano, J., Hansen, S., Touryalai, H. Global 2000: The world's largest public companies. Forbes, May 15 (https://www.forbes.com/global2000).

Ohashi, H. 2003. The role of network effects in the US VCR market, 1978-86. Journal of Economics and Management Strategy 12(4): 447-494.

Özalp, H., Cennamo, C., Gawer, A. 2018. Disruption in platform-based ecosystems. Journal of Management Studies 55(7):1203-1241.

Parker, G.G., Van Alstyne, M.W. 2005. Two-sided network effects: A theory of information product design. Management Science 51(10): 1494-1504.

Parker, G., Van Alstyne, M., Choudary, S.P. 2016. Platform Revolution: How Networked Markets are Transforming the Economy - And How to Make Them Work for You. New York: W.W. Morton and Company.

Rietveld, J., Eggers, J.P.. 2017. Demand heterogeneity in platform markets: Implications for complementors. Organization Science 29 (2): 304-32.

Rochet, J.C., Tirole, J. 2003. Platform competition in two-sided markets. Journal of the European Economic Association 1(4): 990-1029.

Rochet J.C., Tirole J. 2006. Two-sided markets: a progress report. Rand Journal of Economics 37: 645667.

Rysman, M., 2009. The economics of two-sided markets. Journal of Economic Perspectives 23 (3): 125143.

Schilling, MA. 2002. Technology success and failure in winner-take-all markets: the impact of learning orientation, timing, and network externalities. Academy of Management Journal 45: 387-398.

Simcoe, T. Watson, J.2018. Forking, fragmentation, and splintering. Working Paper, Boston University.

Shapiro C. 1999. The art of standards wars. California Management Review 41(2): 8-32.

Shapiro C., Varian, H.R. 1998. Information Rules: A Strategic Guide to the Network Economy. Harvard Business School Press: Cambridge, MA.

Shipilov, A., Gawer, A. 2020. Integrating research on inter-organizational networks and ecosystems, Academy of Management Annals 14(1).

Shy, O. 1996. Technology revolutions in the presence of network externalities. International Journal of Industrial Organization 14(6): 785-800.

Srinivasan A., Venkatraman, N. 2010. Indirect network effects and platform dominance in the video game industry: A network perspective. IEEE Transactions on Engineering Management 57(4): 6617-673.

Srinivasan, A., Venkatraman, N. 2018. Entrepreneurship in digital platforms: A network-centric view. Strategic Entrepreneurship Journal 12(1): 54-71.

Stremersch, S., Tellis, G. J., Franses, P. H., Binken, J. L. 2007. Indirect network effects in new product growth. Journal of Marketing 71(3): 52-74. 
Tellis, G., Yin, E. and Niraj, R. 2009. Does quality win? Network effects versus quality in high-tech markets. Journal of Marketing Research, 46(2): 135-149.

Thomas, L., Autio, E., Gann, D., 2014. Architectural leverage: Putting platforms in context. Academy of Management Perspectives 28(2): 198-219.

Tiwana, A. 2015. Evolutionary Competition in Platform Ecosystems, Information Systems Research 26(2): 266-281.

Tiwana A., Konsynski, B., Bush, A.A. 2010. Platform Evolution: Coevolution of platform architecture, governance and environmental dynamics. Information Systems Research 21(4): 675-687.

Venkatraman, N., Lee, C.H. 2004. Preferential linkage and network evolution: a conceptual model and empirical test in the U.S. video game sector. Academy of Management Journal 47: 876-892.

Von Hippel, E., Katz, R. 2002. Shifting innovation to users via toolkits. Management Science 48(7): 821833.

Wareham J., Fox, P.B., Cano Giner, J.L. 2014. Technology ecosystem governance. Organization Science 25(4): 1195-1215.

West, J. 2003. How open is open enough?: Melding proprietary and open source platform strategies. Research Policy, 32(7): 1259-1285.

Whinston, M. 1990. Tying, foreclosure and exclusion. American Economic Review 80(4): 837-59.

Yoffie, D, Kwak, M. 2006. With friends like these: the art of managing complementors. Harvard Business Review, September 2006.

Zhu, F. Iansiti, M. 2012. Entry into platform-based markets. Strategic Management Journal 33(1): 88106. 


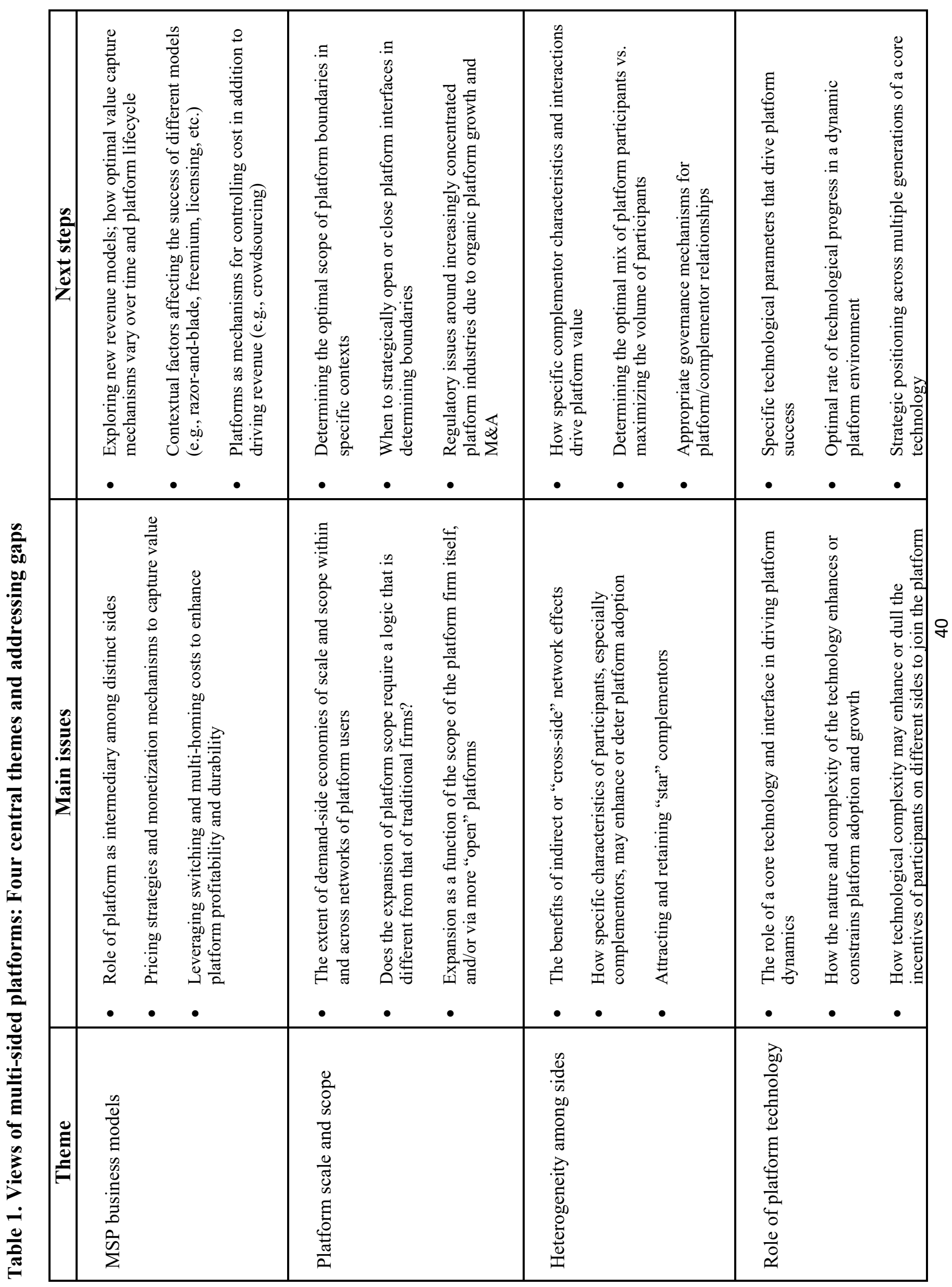


